\title{
АДАПТАЦИОННЫЕ МЕХАНИЗМЫ ПОКОЛЕНИЯ Z В УСЛОВИЯХ СТРЕССА, ВЫЗВАННОГО САМОИЗОЛЯЦИЕЙ ИЗ-3А ПАНДЕМИИ COVID-19
}

\section{ADAPTIVE MECHANISMS OF GENERATION Z UNDER STRESS CAUSED BY SELF-ISOLATION DUE TO THE COVID-19 PANDEMIC}

\section{O. Vasilyeva}

Summary: The article is devoted to the study of the dynamics of the state of young people during the quarantine period associated with the COVID-19 pandemic. Forced self-isolation became a stressful factor for the study group, in which representatives of the youth audience showed themselves in different ways. The aim of the study was to assess the behavioral states and psychoemotional reactions of Generation Z representatives under stressful conditions. Methods: Research methodsanalysis of secondary data from open sources and primary research through an Internet survey. Results: The result was revealed in the study group metaprograms that form multidirectional mental, emotional and behavioral responses to stress caused by the situation with forced isolation. Practical recommendations on the development of adaptation mechanisms in generation Z, developed with the help of digital technologies, to which modern youth is loyal, are proposed. Conclusions: Forced self-isolation for many has become a stressful factor, and a kind of litmus for determining the degree of stress resistance of buzzers. The results of the conducted research can be useful for employers, educational structures and public organizations interested in the youth audience.

Keywords: self-isolation, pandemic, COVID-19, youth, generation Z, behavioral activity, emotional state, stress, adaptation.

\section{Ввецение}

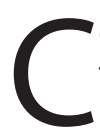

егодня ведутся многочисленные обсуждения на тему ценностных ориентиров и жизненных установок молодого поколения, как его принято называть, поколения Z. Поведенческие и когнитивные особенности молодых людей, рожденных в цифровую эпоху, вызывают живой интерес как среди исследователей, так и среди делового сообщества. На сегодняшний день в мире насчитывается 1,2 миллиарда молодых людей в возрасте от 15 до 24 лет, что составляет 16,5\% населения планеты. По прогнозам к 2030 году этот показатель возрастет на 7 \% и достигнет почти 1,3 миллиарда человек. В России молодежь насчитывает 24,3 млн. человек. [1] Через 10-20 лет эта категория населения будет определять экономико-политическое, научно-технологическое и социокультурное устройство как нашей страны, так и мира
Васильева Ольга Анатольевна старший преподаватель, ФГБОУ ВО «Государственный Университет Управления», Москва oa_vasilyeva@guu.ru

Аннотация: Статья посвящена исследованию динамики состояния молодежи в период карантина, связанного с пандемией COVID-19. Вынужденная самоизоляция стала стрессогенным фактором для исследуемой группы, в которой представители молодежной аудитории проявили себя по-разному. Цель: Целью исследования стала оценка поведенческих состояний и психоэмоциональных реакций представителей поколения Z в стрессовых условиях. Методы: Методы исследования - анализ вторичных данных из открытых источников и первичное исследование посредством интернет - опроса. Результаты: Результатом стали выявленные у исследуемой группы метапрограммы, формирующие разнонаправленные ментальные, эмоциональные и поведенческие реакции на стресс, вызванный ситуацией с вынужденной изоляцией. Предложены практические рекомендации по развитию адаптационных механизмов у поколения Z, вырабатываемых с помощью цифровых технологий, к которым лояльна современная молодежь. Выводы: Вынужденная самоизоляция для многих стала стрессовым фактором, и своего рода лакмусом для определения степени стрессоустойчивости зуммеров. Результаты проведенного исследования могут быть полезны работодателям, образовательным структурам и общественным организациям, интересующимся молодежной аудиторией.

Ключевые слова: самоизоляция, пандемия, COVID-19, молодежь, поколение $Z$, поведенческая активность, эмоциональное состояние, стресс, адаптация.

в целом. Поэтому уже сейчас важно понимать и анализировать реакции зуммеров на происходящие в мире явления. Чтобы в дальнейшем преодолеть барьеры, связанные со сменой поколений, выработать превентивные меры в различных областях для смягчения переходного периода. Важно отметить, что такой фактор, как физическое и психологическое здоровье молодых людей, лежит в основе здоровой нации в ближайшем будущем.

Данная статья посвящена исследованию поведенческих и когнитивных реакций российской молодежи, проявившихся в период самоизоляции из-за пандемии COVID-19. Вынужденная самоизоляция для многих стала стрессовым фактором, и своего рода лакмусом для определения степени стрессоустойчивости зуммеров. Результаты исследования могут быть полезны работодателям, образовательным структурам и общественным 
организациям, интересующимся молодежной аудиторией.

Ситуация с коронавирусной инфекцией перевернула представления о привычном мироустройстве, жизнедеятельности институциональных систем, ценностных ориентиров в обществе. Глобальная пандемия стала сильнейшим стрессором для человечества. На начало 2021 года в мире подтверждено 97495558 случаев заболевания COVID-19, зарегистрированных летальных исходов - 2089460 случаев. В РФ статистика по подтвержденным заболеваниям - 3655839 случаев, по летальным исходам - 67832 случаев соответственно. [2] В течение всего 2020 года велась напряженная работа по нормализации ситуации, так выздоровело на январь 2021 года 53 735201 чел. в мире (в РФ - 3054218 чел.). По всему миру разрабатывались вакцины, в частности Россия провела эту работу успешно, выпустив и зарегистрировав три вида вакцины от коронавирусной инфекции. Усилия по снижению воздействия COVID-19 на человеческий организм продолжаются, и по-прежнему требуют мобилизации и согласования действий со стороны медицинских учреждений, государственных органов, населения и деловых структур. Основными мерами борьбы с коронавирусной инфекцией является ношение масок и перчаток в общественных местах, социальная дистанция, закрытие культурно-развлекательных учреждений, домашний режим, дистанционное образование и удаленная работа. [3]

Длительный режим вынужденной самоизоляции, введенный в конце марта 2020 года в РФ, не мог не сказаться на поведении и эмоциональном состоянии населения нашей страны. Несмотря на то, что о прямом влиянии коронавирусной инфекции на мозг пока говорить рано (специалисты анонсируют итоги исследований в данной области только на конец 2021 года), выявлены случаи повышенной тревожности, психические расстройства и бессонница в 20-30\% случаев после перенесенной болезни. [4] Второй период самоизоляции, начавшийся осенью 2020 года в РФ, прошел несколько легче весеннего. Однако адаптация к ограничениям попрежнему вызывает сложности, а вынужденная самоизоляция - сопротивление. Об этом можно судить по индексу самоизоляции, который введен как интегрированный показатель для измерения уровня ежедневной городской активности и рассчитывается на основе данных об использовании приложений и сервисов компании Яндекс. [5] Для Москвы, как и других крупных городов РФ, этот показатель имел относительно низкое значение $15-35 \%$ только в первую волну самоизоляции с конца марта до середины мая. Осенние же показатели демонстрируют высокое значение (65 - 75\%) данного показателя городской активности. Причин нарушения режима самоизоляции множество, но в дальнейшем мы будем фокусироваться на факторах, влияющих на саморегуляцию поведения индивида в стрессовых условиях и его психоэмоциональные реакции.

\section{Материалы и методы}

Целевой аудиторией исследования стали представители поколения Z. Термин стал популярным, благодаря теории поколений Н. Хова и У. Штрауса, в которой авторы предлагают делить людей на группы, с привязкой к периоду рождения. Так, рожденные в один промежуток времени люди (условно 20-летний период) развиваются под воздействием одинаковых факторов внешней среды, в связи с чем у них формируются схожие ценностные установки и поведенческие ориентации. Генерации получили названия X, Y и Z. [6]. В данном случае нас интересует поколение $Z$ (зуммеров), людей, рожденных в 2000-х годах. Основными характеристиками молодого поколения называют высокую включенность в информационные потоки и процессы, дефицит реального общения, развитую многозадачность и, как следствие, проблемы с удержанием внимания. У них есть собственная позиция, разносторонние интересы и более высокий уровень предприимчивости по сравнению с предыдущими поколениями. Им сложно принимать решения из-за особенностей воспитания и взаимодействия со старшим поколением. Z довольно прагматичны в части планирования будущего, а еще они страдают от страха упустить что-то важное. Поэтому они всегда находятся в авангарде новых веяний и сохраняют высокую конкурентоспособность [7]. В скором времени к этим качествам может добавиться умение справляться с внешними стрессогенными факторами. Поверхностное наблюдение за молодежью в период пандемии показывает, что одни расценивают вынужденные ограничения в условиях самоизоляции как проблему, для других самоизоляция открывает новые возможности.

Проблема исследования заключается в отсутствии актуальной информации об адаптационных механизмах у поколения Z в условиях воздействия стрессогенных факторов. Цель исследования - определить типичные реакции зуммеров на стрессогенные факторы, вызванные вынужденной самоизоляцией, проанализировать влияние глубинных установок (метапрограмм) на поведение и эмоциональное состояние представителей поколения Z в этот период, а также разработать практические рекомендации по развитию адаптационных механизмов. Теоретическими методами исследования выступили системный анализ и синтез, критический анализ, обобщение и объяснение, а также методы ситуационного, логического и статистического анализа, направленные на решение поставленной задачи. В процессе исследования применялись следующие методы сбора эмпирической информации: анализ вторичных данных из открытых источников и первичное исследование эмоциональных состояний и поведенческих реакций на стрессогенные факторы у поколения Z посредством интернет-опроса на платформе Sociotrix.com [8]. 
Научная новизна данной работы заключается в том, что впервые проведен анализ когнитивных, эмоциональных и поведенческих реакций представителей молодежной аудитории в условиях вынужденной самоизоляции. Пандемия COVID-19 способствовала созданию мощного внешнего стрессогенного фактора, который затронул большой пласт населения, в том числе и молодежи. Данные условия стали ключевой компонентой, определяющей новизну работы.

Для выявления факторов, влияющих на саморегуляцию поведения представителей поколения Z в стрессовых условиях, было проведено эмпирическое исследование.

\section{Аитературный обзор}

Теоретической основой для проведения данного эмпирического исследования послужили работы Г. Селье, Э. Хейма, А. Хомича, С. Хобфолла, Дж. Роттера [9-13]. Понятие стресса введено канадским физиологом Г. Селье и определено, как комплексный процесс, включающий непременно и физиологические и психологические компоненты. При реакции стресса человеческий организм мобилизует внутренние ресурсы для защиты и адаптации к возникшей ситуации. При анализе внешних причин возникновения стресса используется понятие стрессоров и экстремальных условий. Стрессоры - это неблагоприятные, значительные по силе и продолжительности внешние и внутренние воздействия, ведущие к возникновению стрессовых состояний. [9]

Процесс протекания стресса проходит следующие стадии:

1. Реакция тревоги. Для этой фазы характерна мобилизация защитных свойств организма. При этом его функционирование происходит с большой нагрузкой. Отмечено, что к завершению этой стадии в большинстве случаев у индивидуумов повышается работоспособность.

2. Стадия сопротивляемости. Для нее характерен сбалансированный расход адаптационных ресурсов организма.

3. Стадия истощения. Адаптационные ресурсов организма на исходе. Требуется вмешательство медицинских работников и специализированная помощь по выводу индивида из этой стадии.

Ресурсная концепция С. Хобфолла объясняет возникновение психологического стресса и риска болезней адаптации в случае нарушения баланса между потерей и приобретением персональных ресурсов. Развитие психологического стресса возможно в случаях угрозы или фактической потери ресурсов, а также когда отсутствует адекватное возмещение истраченных ресурсов. [10] Ситуация с вынужденной самоизоляцией в период пандемии COVID-19 соответствует ситуации возникновения психологического стресса, и, соответственно, интересная с точки зрения изучения раскрытия адаптационных потенциалов исследуемой целевой аудитории. К адаптационным ресурсам личности относят эмоциональные, мотивационно-волевые, когнитивные и поведенческие конструкты, которые личность актуализирует в условиях стрессовых ситуаций. Психолог Э. Хайм предложил ситуационно-специфические механизмы борьбы со стрессом, которые условно распределил в соответствии с основными сферами психической деятельности человека: когнитивные, эмоциональные и поведенческие механизмы. [11] Оценка информации, поступающей из внешней среды, в большей степени определяется неосознанно функционирующими механизмами мышления. Эти механизмы получили название метапрограммы [12] Основная роль метапрограмм состоит в фильтрации и сортировке воспринимаемой извне информации. Метапрограммы влияют на формирование личностных особенностей человека, его ценностных установок, структуру восприятия и поведенческие реакции. Уровень субъективного контроля, введенный американским психологом Дж. Роттером, определяет оценку индивидуумом раздражителей внешней среды и его дальнейшую реакцию. Это психологический фактор представляет собой склонность человека приписывать ответственность за происходящие в жизни события и результаты своей деятельности внешним силам (экстернальный, внешний локус контроля), либо собственным способностям и усилиям (интернальный, внутренний локус контроля). [13] Таким образом, вышеобозначенные концепции послужили теоретико-методологической основой для составления опросника на выявление уровня поведенческой активности, эмоционального состояния и реакций на внешний стрессоген при проведении первичного исследования представителей поколения Z, находящихся в ситуации вынужденной самоизоляции из-за пандемии COVID-19.

В исследовании приняли участие 911 человек в возрасте от 14 до 25 лет. Молодым людям было предложено пройти опросник, содержащий 21 вопрос с единичными, множественными и открытыми вариантами ответов. Далее будут представлены ответы респондентов на предложенные вопросы. Открытый вопрос, связанный с возникающими у респондентов ассоциациями о периоде самоизоляции из-за пандемии COVID-19, выявил следующее соотношение позитивных / нейтральных / негативных образов о пережитом периоде. Так, положительно высказались 20\% опрошенных - среди распространенных ассоциаций: отдых, возможности, творчество, саморазвитие, спокойствие. Нейтральными ассоциациями поделились $42 \%$ участников исследования. Основные ассоциации о периоде изоляции: работа/учеба, дом, сон, карантин, уборка. Негативные образы о пережитом времени сохранились у $38 \%$ респондентов. Среди популярных ассоциаций: негативные эмоциональные состояния (тоска, депрессия, смерть, апатия, усталость, пани- 
ка, опасность, одиночество), зависимость от интернета (сериалы, дистанционное общение), вредные привычки (алкоголь, заедание стресса, лень).

При этом на уточняющий вопрос «Как Вы воспринимаете самоизоляцию» были получены следующие ответы. Подавляющее большинство респондентов $67,4 \%$ (614 чел.) воспринимали самоизоляцию как необходимую меру безопасности. Треть опрошенных 36,1\% (329 чел.) сделали акцент на напряженном времени учебы/ работы. Также треть участников исследования выделила этот период, как возможность для саморазвития, время заняться собой и привести в порядок тело, мысли, эмоции (30,2\% и 31,7\% соответственно). Близкие ответы, касающиеся наведения порядка в окружающем пространстве, получены от 12\% участников. Нашлись молодые респонденты (127 чел., 13,9\% опрошенных), которые провели карантин в развлечениях и веселье. Период самоизоляции, как время для восстановления сил и энергии, обозначили 19,1\% (174 чел.) опрошенных. Оценили период карантина, как возможность заняться давно откладываемыми делами, 28,3\% (258 чел.) респондентов. Отдельно стоит отметить негативные оценки участников исследования. Так, вынужденная самоизоляция воспринималась, как мучительное времяпрепровождение и вынужденное прерывание общения 19,9\% и 19,8\% опрошенных соответственно; как принудительную ограничивающую свободу меру 17,6\% участников опроса; как тяжелый период, приводящий к деградации, обозначило $12,2 \%$ респондентов. Так как участники в рамках данного вопроса имели возможность выделить до трех вариантов предложенных ответов, то пропорции позитивного и негативного восприятия молодыми людьми периода самоизоляции, связанного с пандемией COVID-19, разделились на $77 \%$ и 23\% соответственно. Можно сделать вывод о том, что большая часть представителей поколения Z, принявшая участие в исследовании сумела приспособиться к обстоятельствам.

Для исследования динамики поведенческой активности молодежи был задан вопрос «Как изменилась Ваша активность в период изоляции?». Процент респондентов, которые отметили позитивную динамику своей поведенческой активности, проявившуюся под действием внешнего стрессогена, составил 30\%. Среди них $9 \%$ отметили значительное повышение, связанное с появлением дополнительных, ранее не предусмотренных дел, и $21 \%$ аудитории связал повышение активности с необходимостью совмещать домашние и рабочие дела. Снижение поведенческой активности в период самоизоляции отметили $45 \%$ респондентов, при этом $18 \%$ из них определили свою активность на уровне удовлетворения базовых биологических потребностей (еда, сон, просмотр развлекательного контента в сети Интернет). Четверть участников опроса определили свою активность в период самоизоляции, как неизменившуюся (25\%). Еще один вопрос в рамках определения динамики поведенческой активности был нацелен на выявление сценарных паттернов поведения, учитывая фазы и циклы проживания стрессовых ситуаций личностью. Весь период условно разделен на 3 фазы: начальная (первичная реакция на стресс), реактивная (послестрессовое состояние) и адаптационная (выработанное поведение с учетом изменений). Респонденты описали свои сценарии поведенческой активности в период самоизоляции следующим образом:

- 16,8\% (153 чел.) - сначала энтузиазм и повышенная активность (1 фаза) - потом усталость и отдых (2 фаза) - далее режим деятельности равномерный и соответствует моим биоритмам (3 фаза)

- 15,6\% (142 чел.) - сначала шок, апатия и упадок сил (1 фаза) - потом постепенная адаптация (2 фаза) и выход на привычный ритм (3 фаза)

- 26,5\% (241 чел.) - сначала период расслабления и даже безделья (1 фаза) - потом активное закрытие «возникших дыр» и накопившихся дел (2 фаза) далее устоявшийся повышенный ритм (3 фаза)

- 19,3\% (176 чел.) - без видимых скачков - спокойно и в привычном режиме

- 15,5\% (141 чел.) - без видимых скачков - весь период пониженная активность

- 4,5\% (41 чел.) - без видимых скачков - весь период повышенная активность

- 2\% (17 чел.) - обозначили цикличность фаз повышения и снижения поведенческой активности с высокой амплитудой эмоциональных реакций

Таким образом, сценарии поведенческой активности среди молодежи в период самоизоляции из-за пандемии COVID-19 можно условно разделить на два типа по критерию психоэмоциональной регуляции: эмоционально нестабильную (61\% респондентов) и условно стабильную (39\% респондентов), которые отражают способность нервной системы личности переходить в фазы возбуждения и торможения. Эти реакции, и как следствие, сценарии поведения, привязаны к темпераменту личности и накопленному поведенческому опыту.

Подтверждением того факта, что эмоциональное состояние напрямую влияло на поведенческую активность молодежи в период пандемии, стали ответы респондентов на вопрос «Оцените в \%-ом отношении реализацию планов в период самоизоляции». Так, 38,2\% участников опроса выразили мнение о том, что их деятельность в данный период зависела от настроения; еще 14,6\% опрошенных заявили о крахе большей части планов и 9,1\% высказались о периоде застоя в деятельности. Высокую результативность в реализации планов обозначили 7,6\% молодых людей; удовлетворенность своей адаптацией к ситуации и достижение поставленных целей было характерно для 30,5\% респондентов. Структуру деятельности молодежи в период самоизоляции позволил сформировать вопрос «Что из перечисленного Вам удалось реализовать?». Наиболее популярным времяпрепровожде- 
нием среди респондентов стали отдых и развлечения: просмотр фильмов и развлекательного контента (49,5\% ответов), серфинг в сети Интернет (31,1\% ответов), полноценный сон (31,3\% ответов). Практическая деятельность также была выделена респондентами: наведение порядка в окружающем пространстве (43\% ответов), реализация учебных и рабочих задач (29,5\% ответов). Третье место в структуре деятельности молодежи в период самоизоляции из-за пандемии COVID-19 заняло самосовершенствование тела и духа: чтение книг (26,8\% ответов), занятия спортом (25,4\% ответов), языковая практика (8,5\% ответов). Четвертую позицию в структуре деятельности заняла внутренняя сфера. Так, наведение порядка в мыслях и чувствах, а также планирование будущего получено в $22 \%$ и $11,7 \%$ ответов соответственно. Стоит отметить, что активность в межличностной сфере в формате онлайн-коммуникаций отмечена только в 20,5\% ответов респондентов. Замыкает структуру деятельности в период карантина творчество: кулинария (17,6\% ответов), рисование (15,7\% ответов), музицирование $(11,1 \%$ ответов). Таким образом, процентное соотношение направленности личностных ресурсов для организации деятельности молодежи в период самоизоляции на внутриличностную и межличностную сферы составило 94:6. При этом дальнейшая конкретизация активностей и выяснение деталей времяпрепровождения во время карантина выявила нестыковку в оценке самовосприятия и осознанном распределении личностных ресурсов. Анализ устойчивых способов действий и оценок (метапрограмм) зуммеров, участвовавших в исследовании, позволил сформировать более четкое понимание поведения и эмоциональных проявлений в стрессовых ситуациях. В предложенном опроснике анализировались такие метапрограммы, как «активность - рефлексия», «стремление - избегание», «внутренняя референция внешняя референция», «процесс - результат».

Активность - рефлексия. Данная установка характеризует стиль достижения поставленных целей. Активные личности зачастую решительны, целенаправленны, добиваются результата и действуют энергично. Для рефлексирующего типа наиболее значимы анализ и понимание ситуации перед тем, как предпринять шаги в отношении реализации задач. Они производят впечатление основательных, вдумчивых и рассудительных личностей. В ходе опроса выяснилось, что в период самоизоляции проявили свою активность и были производительными 42,6\% респондентов, а посвятили данный период размышлениям 57,4\% участников исследования. При этом активно общались 54,4\%, чувствовали себя одинокими 45,6\% представителей поколения Z, принявших участие в опросе.

Стремление - избегание (мотивация «к - от»). Данная метапрограмма описывает мотивационную установку, которая формируется при решении жизненных задач. Так, мотивация «К» побуждает индивида ставить цели, строить планы, мечтать. Часто они готовы идти на риск, игнорируя сложности и препятствия. Поведение представителей мотивации «ОТ» обусловлено избеганием трудностей, опасностей и трудных ситуаций. В ходе опроса выяснилось, что 40,1\% респондентов поколения Z в период самоизоляции радовались новым возможностям и смогли многое сделать, в то время как 59,9\% опрошенных вынужденно выполняли имеющиеся задачи.

Референция (внутренняя - внешняя). Данная установка напрямую связана с уровнем субъективного контроля и демонстрирует фокус направленности на себя или во вне при принятии решений. Так, при внутренней референции индивид полагается на собственную точку зрения и ответственность за происходящие в жизни события предпочитает брать на себя. При внешней референции ситуация обратная - при принятии решений важна точка зрения окружения и ответственность также возлагается на нее. Опрос показал, что в период самоизоляции старались контролировать своё состояние и ситуацию по мере возможности - 57,4\% участников исследования. Расслабились и отдались воле обстоятельств 42,6\% молодых людей. Многие участники отметили осознание степени своего влияния на внутриличностную сферу 59,6\% зуммеров осознали, что сильно влияют на то, что с ними происходит; 40,4\% высказали противоположную точку зрения.

Процесс - результат. Данная метапрограмма показывает фактор получения удовольствия в ходе выполнения той или иной задачи. Для индивида, ориентированного на достижение результата, глубинным мотивом является получение удовлетворения в конечной точке. Для процессно-ориентированной личности удовольствие достижимо в ходе выполнения работы. Результаты опроса показали, что среди участников 69,3\% получают удовлетворение, когда наблюдают результат и только 30,7\% вдохновляются процессом. При этом стрессовую ситуацию, связанную с вынужденной самоизоляцией, легче перенесли зуммеры с процессной метапрограммой, занимаясь саморазвитием или творчеством.

Отдельное внимание стоит уделить эмоциональному состоянию участников исследования. Большая часть респондентов (59,2\%) сообщила, что в период вынужденной самоизоляции произошло эмоциональное истощение, другая часть (40,8\%) заявила об эмоциональном наполнении. В 80,5\% случаев у участников исследования доминировали установки на преодоление стресса в сложный период времени, связанный с самоизоляцией, и лишь в 19,5\% случаев проявлялся фатальный характер мыслей. Поведенческие реакции на стресс были связаны с погружением в любимое дело (19,2\%), новым начинанием (4,9\%), переключением на задачи близких людей $(19,2 \%)$, самовнушением $(15,7 \%)$, одиночеством $(17,9 \%)$, вредными привычками $(16,1 \%)$ и получением сторонних 
консультаций (7\%).

\section{Результаты}

Таким образом, наиболее устойчивыми к стрессу, вызванному вынужденной самоизоляцией в период пандемии из-за COVID-19 оказались представители молодого поколения Z, с метапрограммами стремления, активности и внутренней референции. Именно эти метапрограммы стали основой быстрой адаптации к внешним стрессогенным условиям. Большая часть молодежи, принявших участие в исследовании, продемонстрировала устойчивые способы действия и оценок, характерные для адаптивных, стрессоустойчивых личностей, которые используют внешние обстоятельства с пользой для себя и окружения. Стоит отметить, что метапрограмма «проиесс - результат» не обнаружила выраженного негативного влияниям на индивида в исследуемый период. Наиболее сложно переживали самоизоляцию зуммеры с базовыми метапрограммами «внешняя референция» и «рефрлексия». Фатальные настроения и уход от реальности через вредные привычки характерны именно для этой группы исследуемых. Данные говорят о недостаточно развитых механизмах регуляции в стрессовых условиях у поколения Z. Особенно стоит сказать об уходе в виртуальную реальность, как выраженную поведенческую особенность современной молодежи. Именно базовые метапрограммы определяют вектор влияния сети Интернет на состояние индивида.

Если говорить о рекомендациях по повышению адап- тационных механизмов к стрессовым воздействиям у поколения Z, то использование виртуальной реальности для смягчения стрессогенов и выработки устойчивости может стать решением в данной ситуации. Так, использование набирающих популярность AR/VR-технологий для снятия эмоционального напряжения будет востребовано цифровым поколением. Виртуальная реальность (VR - virtual reality) полностью погружает пользователя в искусственную среду с помощью специального оборудования. Дополненная реальность (AR - augmented reality) позволяет увидеть виртуальные предметы в реальном виде, используя камеру смартфона. [14] Голосовые помощники, выполняющие роль психолога-консультанта, могут стать альтернативной терапией в условиях самоизоляции. Технологии продолжают развиваться, цифровизация становится частью повседневной жизни, и молодежь является ее лояльным потребителем.

\section{Зак^ючение}

В заключении стоит еще раз сделать акцент на важности изучения форм мыслительной активности, эмоциональных реакций и поведенческих сценариев молодого поколения, вступающего во взрослую жизнь. Какой бы сложной не казалась ситуация с вынужденной самоизоляцией из-за пандемии COVID-19, она позволила создать естественные стрессовые условия для исследования. Дальнейшее изучение поведенческих сценариев поколения Z необходимо благополучия общества в ближайшем будущем.

\section{ЛИТЕРАТУРА}

1. Организация объединенных наций. Молодежь [Электронный ресурс] - Режим доступа: https://www.un.org/ru/sections/issues-depth/youth-0/index.html

2. Карта распространения коронавируса COVID-19 [Электронный ресурс] - Режим доступа: https://covid.osnova.news/self-isolation/

3. Официальный сайт мэра Москвы [Электронный ресурс] - Режим доступа: https://www.mos.ru/city/projects/measures/

4. Коношевич В. Мысли о суициде и стрессовое расстройство: как ковид влияет на психику [Электронный ресурс] - Peжим доступа: https://birdinflight.com/ ru/mir/20201127-kovid-vs-psihika.html

5. Индекс самоизоляции [Электронный ресурс] - Режим доступа: https://yandex.ru/company/researches/2020/podomam

6. Howe, N., Strauss, W. The Fourth Turning: What the Cycles of History Tell Us About America's Next Rendezvous with Destiny. New York: Broadway Books, 1997

7. Стиллман Д. Семь ключевых особенностей поколения Z [Электронный ресурс] - Режим доступа: https://hbr-russia.ru/management/upravlenie-personalom

8. Поведенческая активность молодежи в условиях самоизоляции из-за пандемии COVID-19. Sociotrix. [Электронный ресурс] - Режим доступа: https:// sociotrix.com/form?id=781

9. Три стадии стресса. Лаборатория ДНКОМ [Электронный ресурс] - Режим доступа: https://dnkom.ru/0-kompanii/stati/stress/stadii-stressa/

10. Hobfoll S.E. Social Support: Will you be there when I need you? In N. Vanzetti and S. Duck (eds.), A lifetime of relationships. California: Brooks / Cole Publishing Co, 1996. - p. 12

11. Блазер А., Хайм Э. Проблемно-ориентированная психотерапия. - Пер. Л.С. Каганова - М.: Класс, 1998

12. Холл М., Боденхамер Б. 51 метапрограмма НЛП - СПб.: Прайм-ЕВРОЗНАК, 2007 - 347с.

13. Rotter J.B. Social learning and clinical psychology. - New York: Prentice-Hall, 1954

14. VR, AR, CTR: как виртуальная реальность помогает продажам - Режим доступа: https://prodasch.ru/ 